Research Article

\title{
Technical and Scale Efficiency in Spanish Urban Transport: Estimating with Data Envelopment Analysis
}

\author{
I. M. García Sánchez \\ Department of Administration and Business, Faculty of Economy, University of Salamanca, \\ Campus Miguel de Unamuno, Edificio FES, 37007 Salamanca, Spain \\ Correspondence should be addressed to I. M. García Sánchez, lajefa@usal.es
}

Received 10 October 2008; Revised 15 January 2009; Accepted 24 February 2009

Recommended by Walter J. Gutjahr

The paper undertakes a comparative efficiency analysis of public bus transport in Spain using Data Envelopment Analysis. A procedure for efficiency evaluation was established with a view to estimating its technical and scale efficiency. Principal components analysis allowed us to reduce a large number of potential measures of supply- and demand-side and quality outputs in three statistical factors assumed in the analysis of the service. A statistical analysis (Tobit regression) shows that efficiency levels are negative in relation to the population density and peak-to-base ratio. Nevertheless, efficiency levels are not related to the form of ownership (public versus private). The results obtained for Spanish public transport show that the average pure technical and scale efficiencies are situated at 94.91 and $52.02 \%$, respectively. The excess of resources is around $6 \%$, and the increase in accessibility of the service, one of the principal components summarizing the large number of output measures, is extremely important as a quality parameter in its performance.

Copyright (c) 2009 I. M. García Sánchez. This is an open access article distributed under the Creative Commons Attribution License, which permits unrestricted use, distribution, and reproduction in any medium, provided the original work is properly cited.

\section{Urban Transport}

Urban transport seeks the mobility of citizens within the municipal area, and it is a service whose importance is on the increase as a consequence of the ever more dynamic changes in life and work. The spreading of the residential areas to the outskirts of towns, the locating of economic activities in industrial estates, and the moving of faculties to university campuses have created a greater need for access to these places, which public transport must cover (Law 7/1985 Regulating the System of Local Authorities), especially for those who depend on it.

This service, as Prior [1, page 430] states, is a substantial component of the quality of life that is offered to citizens. For this reason, the political authorities usually impose 
obligations on Urban Public Transport companies, and these obligations can be manifested in different ways: limitation of prices, minimum level of service to those users that do not have other means of transport, or the maintenance of routes or frequencies that are not economically justifiable.

The parameters that define its performance cause special relevance to be given to the measurement of the service from the criterion of efficiency or estimation of the fit between the resources used in the production or development of the appropriate quantity and quality of goods or services in a suitable time. And, because of the obligations imposed on the operating companies, a revenue-based market test is an inappropriate measure of efficiency. We therefore focus on technical efficiency using inputs and outputs expressed in physical terms.

Technical efficiency may be split into pure technical efficiency and scale efficiency, in other words, the nature of technical inefficiencies can be due to the inefficient implementation of the production plan in converting inputs to outputs (pure technical inefficiency) and/or due to the divergence of the decision making units (DMU) from the most productive scale size (scale inefficiency). Decomposing technical efficiency allows us to gain insight into the main sources of inefficiencies.

Among the factors explaining gaps in efficiencies, issues such as ownership, risk allocation, use of tendering, level of competition, and so on, are considered within the efficiency analysis in several papers-for example, [2-7]. In Spain, although the provider could be a public agency or a private company, municipalities make all production decisions both for public and private agents; moreover, the duration of the contracts is generally ten years, and there is only one provider in each municipality, so there is no level of competition. Thus it would only be of interest to analyze the effect of ownership on the levels of efficiency.

This leads us to establish the objectives of this research, on the one hand, the estimation of the technical and scale efficiency of the service with the aim of detecting potential savings in the use of physical resources that would lead to increments in productivity. On the other hand, we test whether the differences in the efficiency index can be explained in terms of the type of ownership (public versus private) adopted by the municipal corporation.

The study is organized as follows: first, a review is made of urban transport production functions, then the methodology of analysis is established, specified in the phases of description of the technique, analysis procedure, and theoretical and statistical selections of the variables. Finally, the results are given, and a set of conclusions are drawn.

\section{Urban Transport Production Function}

Several methods are used for measuring technical efficiency. The first classification would be frontier and nonfrontier techniques.

A huge number of papers use nonfrontier techniques, (e.g., Pucher [8] used correlation coefficients; Karlaftis et al. [9] applied the $t$-test; other studies were addressed to estimating the efficiency base in the application of OLS single-models, embracing principally functional forms, such as Cobb Douglas, Translog, etc., to estimate the production function [10] or cost function [11].) but at present the analyses related to this service focus on estimating efficiency using the frontier methodology (illustrated in Table 1), in particular a nonparametric technique, DEA, which requires fewer assumptions than other techniques regarding the functional form, and finds-in the input-oriented case-the greatest scalar reduction in the input bundle which could yield the given output vector. 
Table 1: Taxonomy of frontier methodologies [12].

\begin{tabular}{lcc}
\hline Functional form & Deterministic & Measurement error \\
Parametric & Corrected OLS, and so forth & $\begin{array}{c}\text { Frontiers with explicit assumptions } \\
\text { (exponential, half-normal, etc.) for the } \\
\text { TE distributions }\end{array}$ \\
Nonparametric & FDH, DEA-type models, and so forth & $\begin{array}{c}\text { Resampling: chance constrained } \\
\text { programming, and so forth }\end{array}$ \\
\hline
\end{tabular}

In some works, moreover, authors applied the DEA models and parametric frontiers to detect divergences in the efficiency indexes obtained between the two approximations $[13,14]$. The results are highly similar, favoring the application of the DEA technique in the analyses, as can be seen in many studies carried out in various countries, for example, the United Kingdom [15-17], Spain [18], France [19-21], Norway [22], Japan [23, 24], the USA [25-29], Italy [30, 31], Taiwan [32], and Canada [33]. Other methods can determine the potential savings for individual production factors, for example, MEA [34] as well as nonradial methods by Färe and Lovell [35].

Although DEA models jointly handle the multiple inputs and multiple outputs characteristic of municipal services, they have several limitations. First, with the basic DEA models there are usually a large number of zero weights in inputs and outputs variables. Second, the inclusion of a large number of inputs and outputs reduces the degrees of freedom of this program and, as a result, the number of efficient units increases.

Thus, in our analysis we applied a procedure that corrects the second problem with DEA by reducing the number of outputs using principal components analysis. The reduction of these variables is necessary since we considered the traditional supply and demand public transport outputs and, unlike previous works, the quality components of the service.

\section{Data Envelopment Analysis}

DEA is a linear program model that extended Farrell's [36] efficiency measurement and generalizes the single-input, single-output ratio measure of the efficiency of a single unit or Decision-Making Unit (DMU) to a multiple-inputs, multiple-outputs setting. A DMU is an entity that produces outputs and uses up inputs. In public transport, each municipality constitutes a DMU, because in Spain the municipalities make all production decisions both for public and private providers.

DEA yields a piecewise linear production surface that, in economic terms, represents the best practice production frontier. By projecting each unit onto the frontier, it is possible to determine the level of inefficiency by comparison to a single reference unit or a convex combination of other reference units. The projection refers to a hypothetical DMU which is a convex combination of one or more efficient DMUs and not an actual DMU.

The first basic DEA model, named CCR, as proposed by Charnes et al. [37], is expressed in ratio form as follows:

$$
\operatorname{Max}\left\{\delta_{0}=\frac{\sum_{r} u_{r} y_{r j 0}}{\sum_{i} v_{i} x_{i j 0}}\right\}
$$




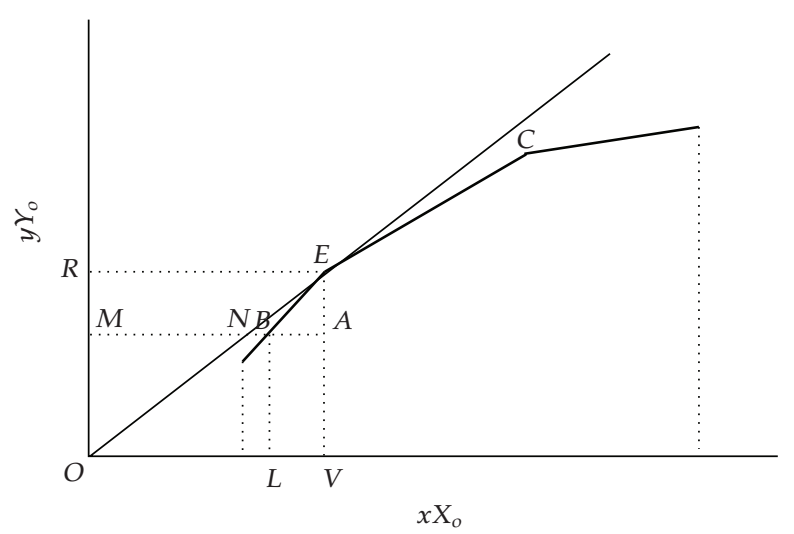

Figure 1: Efficiency measurement [38].

subject to

$$
\frac{\sum_{r} u_{r} y_{r j 0}}{\sum_{i} v_{i} x_{i j 0}} \leq 1 \quad \forall \mathrm{DMU}_{j}, u_{r}, v_{i} \geq 0
$$

where $\delta_{0}$ is the efficiency score of the DMU under analysis; $r$ is the number of outputs; $i$ is the number of inputs; $u_{r}$ is the weight given to output $r ; y_{r j}$ is the amount of output $r$ from unit $j ; v_{i}$ is the weight given to input $i ; x_{i j}$ is the amount of input $i$ to unit $j$.

Given a set of DMUs, the model determines for each DMU the optimal set of input weights and output weights that maximize its efficiency score $\delta_{0}$. According to the dual envelopment form (3.1), the efficiency is defined by reference to the orientation chosen. It is thus possible to estimate a DEA output-oriented model, a DEA input-oriented model and a DEA graph-oriented model.

A score of less than one means that a linear combination of other units from the sample could produce the vector of outputs using a smaller vector of inputs. Mathematically, a DMU is termed efficient if its efficiency rating $\delta_{0}$ obtained from the DEA model is equal to one. Otherwise, the DMU is considered inefficient.

Another version of the basic DEA model that is in common use is Banker et al. [38] model, BCC. The main distinction between the BCC and the CCR models is the introduction of a parameter that relaxes the constant returns to scale (CRS) condition by not restricting hyperplanes, defining the envelopment surface to go through the origin.

The BCC version is more flexible and allows variable returns to scale (VRS); consequently, it measures only pure technical efficiency for each DMU. That is, for a DMU to be considered as CCR efficient, it must be both scale and pure technically efficient. For a DMU to be considered BCC efficient, it only needs to be pure technically efficient. And, if we estimate the ratio efficiency-CCR/efficiency-BCC, we obtain the scale efficiency index.

Figure 1 illustrates these concepts of technical and scale efficiencies. Point $A$ represents the DMU being evaluated. Its overall technical and scale efficiency is measured by the ratio $\mathrm{MN} / \mathrm{MA}$, by comparing point $A$ to point $N$, which reflects the average productivity attainable at the most productive scale size represented by point $E$. The pure technical efficiency of $A$ is measured by the ratio $\mathrm{MB} / \mathrm{MA}$ by comparing it with point $B$ on the efficient production frontier with the same scale size as $A$. Finally, the scale efficiency of $A$ is measured by the ratio 
$\mathrm{MN} / \mathrm{MB}$, so that the overall technical and scale efficiency MN/MA is equal to the production of the technical efficiency MB/MA and the scale efficiency MN/MB:

$$
\begin{aligned}
\text { pure technical efficiency } & =(\mathrm{MB} / \mathrm{MA}), \\
\text { scale efficiency } & =(\mathrm{MN} / \mathrm{MB}), \\
\text { technical efficiency } & =(\mathrm{MN} / \mathrm{MA})=(\mathrm{MB} / \mathrm{MA}) \times(\mathrm{MN} / \mathrm{MB}) .
\end{aligned}
$$

Traditional DEA models implicitly assumed that factors (inputs and outputs) are discretionary, which means that they are controllable and can be set up by the manager. However, in many realistic situations, variables are exogenous and nondiscretionary, so Banker and Morey $[39,40]$ provided a modification to the basic DEA models that permits the DEA solutions to indicate the amount a controllable input can reduce while keeping the noncontrollable input fixed at its current level and quality-based output measures. (DEA can be performed using Frontier Analyst software from Banxia, and we used STATA and SPSS for the other econometric analysis. Note that there are other software packages for DEA analysis (e.g., EMS, DEA-solver, etc.).) This last model is used in our final estimation since we considered several social indicators, statistically significant according to Tobit regression, that are not controlled by public managers.

\section{Aims and Selection of Variables}

This work focuses on the estimation of the technical efficiency-pure technical, and scale- of public urban transport. The study was carried out for 24 Spanish towns representing $21.24 \%$ of the population, all with over 50000 inhabitants. All the municipalities were included since none of them has an outlier profile according to the criteria established by Carrington et al. [41].

We established the following objectives: (i) to estimate the efficiency indexes for the service, given the utility that the DEA technique offers with regard to this matter; and (ii) to contrast whether the differences in efficiency indexes can be explained in terms of the type of ownership (public or private) adopted.

De Borger et al. [12] provided a comprehensive survey of literature on production frontiers for transit operators and found that many important issues remain unresolved, such as the specification of outputs or the characteristics that lie outside the control of the operators, and so forth.

In this paper, we established an analysis procedure that allows us to analyze the bus services accounting for (i) supply, demand, and quality output measures that allow us to capture all the economic motives for providing the services and (ii) the characteristics of the heterogeneity of the transport output as an integral part of the technology description.

To reduce the number of outputs, we ran a principal component factor analysis, and to identify the elements of environmental heterogeneity we applied a Tobit regression.

First, it is necessary to define a set of variables adapted for the control of the aforementioned service. The indicators that represent the functions of this service were selected and grouped into indicators of input, output, and social indicators. Whenever possible, the variables proposed for analysis are presented as whole numbers, (i.e., variables such as kilometers, passengers, etc.) without ratio forms or percentages, in order to avoid elements that interfere with the notion of technical efficiency, according to the recommendation of Golany and Roll [42, page 239]. 


\subsection{Inputs and Outputs}

The three factors most commonly used in literature represent the resources consumed or used in the accomplishment of the service: staff, measured by full-time workers (Input1), fuel consumption (Input2), and the number of operating buses (Input3), "variables all with very significant coefficients in the production function" [43, page 116].

Regarding outputs, the economic analysis of public transport should consider a vector of products, and we considered it appropriate to classify outputs in supply- and demand-side measures. The former would include the vehicles-km (Output1), seating capacity, measured in total seats (Output2), and the number of hours of service (Output3). The latter would include the number of passengers (Output4). The introduction of both types of output in the analysis is justified by a simple but powerful counter-argument, suggesting that as supply indicators allow an adequate description of transit technology, demand factors should play a relevant role in output definitions because if one ignores demand altogether, then the most cost efficient and productive bus operators may be not servicing any passengers $[12$, pages $18,19]$.

Moreover, public transport has a level of quality determined by a set of characteristics such as (i) frequency of the service, measured by means of the ratio Hours of service/ Average time for route (Output5); (ii) comfort associated with a more modern fleet, measured by the inverse of average age of the fleet (Output6), because the newer the fleet, the greater the technological innovation; (iii) the indicator average number of stops per route (Output7) is used to represent the factor of accessibility; (iv) the inverse of accidents and breakdowns suffered is included as a factor to minimize, reflecting the safety level (Output8).

\subsection{Social Indicators}

As reflected below, there are many variables of the surroundings that may have an influence on the level of efficiency of the service and which should be considered in the analysis. We have grouped them into local factors and characteristics of the service.

The local factors reflect the town's demographic and socioeconomic characteristics. The demographic characteristics suggest that the bigger the town, given certain resources, the greater the efficiency expected in the performance of the service. Population density (Social1) is the variable used to represent these factors. It is measured by the ratio population per municipal surface.

The socioeconomic characteristics are reflected by the variable rent per capita (Social2), indicative of the macrolevel of municipal wealth, because we considered that the bus is used mainly by citizens who lived in a municipality with a lower income level, which makes it a key factor in distributive policy. It represents the income of each of the municipality's habitants.

In relation to the characteristics of the service, or the factors that define the environmental setting for the performance of public transport, the following variables were considered relevant: the number of private vehicles in circulation (Social3); the average commercial speed reached by the buses (Social4); the coefficient of intensity in rush hours (Social5); following Miller [44], the variable kilometers covered/routes served (Social6) for defining the increase in the number of places where activities are carried out, which would lead to a broader distribution of passengers; a dummy representing the existence of alternative public transport (Social7), because this situation will imply rivals in the market that will attract potential customers of the bus services. 
Table 2: Output correlation matrix.

\begin{tabular}{lcccccccc}
\hline & Hours & Seats & Vehicles-Km & Passengers & Frequency & Accessibility & Comfort & Safety \\
\hline Hours & - & - & - & - & - & - & - & - \\
Seats & $\mathbf{0 . 9 5 4}$ & - & - & - & - & - & - & - \\
Vehicles-Km & $\mathbf{0 . 9 7 5}$ & $\mathbf{0 . 9 4 7}$ & - & - & - & - & - & - \\
Passengers & $\mathbf{0 . 9 7 1}$ & $\mathbf{0 . 9 4 2}$ & $\mathbf{0 . 9 9 7}$ & - & - & - & - & - \\
Frequency & $\mathbf{1}$ & $\mathbf{0 . 9 5 4}$ & $\mathbf{0 . 9 7 5}$ & $\mathbf{0 . 9 7 1}$ & - & - & - & - \\
Accessibility & -0.023 & 0.255 & -0.019 & -0.029 & -0.023 & - & - & - \\
Comfort & -0.060 & 0.010 & 0.030 & 0.025 & -0.007 & 0.049 & - & - \\
Safety & -0.070 & -0.099 & -0.105 & -0.108 & -0.070 & 0.003 & -0.132 & - \\
\hline \multicolumn{7}{c}{ Bartlett's coefficient: 475.009, P-value: .000 } \\
\hline \multicolumn{7}{c}{ General Sampling Sufficiency: 0.679 } \\
\hline
\end{tabular}

\section{Selection of Statistical Variables}

The initial list of factors to be considered for assessing the performance of the municipalities should be as extensive as possible. There is, however, a problem involving degrees of freedom, which decrease with the number of inputs and outputs considered in the analysis and could lead to a greater number of efficient local authorities. The next steps are addressed to reducing the initial list to one that includes only the most relevant factors.

\subsection{Inputs and Outputs}

The introduction of a large number of variables, according to Banker et al. [45], means an increase in the units considered efficient, owing to reduced degrees of freedom. Thus, we decided to test the correlation between output indicators, numerically greater than those of inputs, obtaining the correlation matrix given in Table 2.

Ten of the twenty-eight correlations (35.71\%) are significant for a confidence level of $99 \%(P$-value $<.01)$; this is an adequate basis for the empirical examination of the sufficiency of the factor analysis. Bartlett's coefficient, which estimates the correlations of all variables jointly, is significant for a confidence level of $99 \%$, and the measure of general sampling sufficiency falls within the range of approval. With these relations and owing to the need to decrease the number of indicators so that the efficient units will be such and not as a consequence of a greater number of variables, we decided to apply a principal components factor analysis (VARIMAX rotation), the one given in Table 3, because no differences exist if the factor-analytic specification is varied.

According to the importance of the coefficient of the variables in each factor, it can be summarized that FACTOR1 reflects the real supply and demand outputs of the service associated with a level of frequency in its performance. FACTOR2 represents the comfort and the security with which the service is performed, and FACTOR3 refers to the degree of accessibility or proximity of the stops that the users of transport have. (In some cases, the value taken by the factor is not positive, which implies that it does not fulfill the condition of positiveness that DEA models require. In order to avoid this situation, the property of invariability will be applied to the conversion demonstrated by Iqbal Ali and Seiford [46] and Pastor [47] for the additive models and the BCC model, which makes it possible to change negative variables into positive ones by adding a fixed amount for all the units, without giving rise to variations in the results of the analysis.) 
Table 3: Matrix of components.

\begin{tabular}{lccc}
\hline & & Varimax rotation & \\
Variables & 1 & Factor & 3 \\
\hline Hours & 0.993 & 2 & -0.03589 \\
Seats & 0.968 & 0.006093 & 0.237 \\
Vehicles-Km & 0.990 & 0.03375 & -0.03452 \\
Passengers & 0.988 & 0.05505 & -0.04523 \\
Frequency & 0.993 & 0.05458 & -0.03568 \\
Accessibility & 0.01727 & 0.004916 & 0.988 \\
Comfort & -0.02423 & 0.01728 & 0.135 \\
Safety & -0.007916 & 0.751 & 0.116 \\
\hline
\end{tabular}

Table 4: CCR-efficiency index and DEA-varying outputs.

\begin{tabular}{lccccc}
\hline Municipalities & DEA-supply & DEA-demand & DEA-quality & DEA-all outputs & DEA-3 factors \\
\hline Alcalá & 100.00 & 76.63 & 66.37 & 100.00 & 49.90 \\
Burgos & 70.29 & 93.72 & 10.77 & 94.60 & 19.95 \\
Castellón & 63.01 & 71.60 & 100.00 & 100.00 & 81.12 \\
Ciudad Real & 100.00 & 67.07 & 64.26 & 100.00 & 39.04 \\
Gijón & 79.00 & 66.03 & 13.64 & 82.39 & 14.57 \\
Girona & 100.00 & 69.11 & 85.77 & 100.00 & 48.28 \\
Lugo & 100.00 & 100.00 & 100.00 & 100.00 & 100.00 \\
Lleida & 59.41 & 64.29 & 18.83 & 66.29 & 19.47 \\
Madrid & 100.00 & 100.00 & 100.00 & 100.00 & 100.00 \\
Mieres & 70.70 & 66.30 & 46.31 & 72.16 & 42.42 \\
Oviedo & 100.00 & 100.00 & 100.00 & 100.00 & 100.00 \\
Palma de Mallorca & 100.00 & 63.71 & 22.76 & 100.00 & 15.24 \\
Ponferrada & 100.00 & 83.88 & 57.96 & 100.00 & 60.05 \\
Sabadell & 89.89 & 93.57 & 12.00 & 93.57 & 23.63 \\
Salamanca & 100.00 & 88.56 & 14.99 & 100.00 & 21.87 \\
San Cugat & 100.00 & 100.00 & 100.00 & 100.00 & 100.00 \\
San Sebastián & 85.84 & 90.97 & 10.60 & 94.54 & 16.21 \\
Santander & 76.14 & 73.39 & 7.18 & 78.14 & 13.90 \\
Santiago Compostela & 100.00 & 60.71 & 17.48 & 100.00 & 26.77 \\
Sevilla & 100.00 & 77.69 & 9.66 & 100.00 & 23.56 \\
Toledo & 100.00 & 100.00 & 100.00 & 100.00 & 100.00 \\
Torrelavega & 100.00 & 100.00 & 100.00 & 100.00 & 100.00 \\
Valladolid & 100.00 & 100.00 & 51.51 & 100.00 & 41.02 \\
Zaragoza & 100.00 & 63.68 & 2.42 & 100.00 & 24.13 \\
\hline Average efficiency & 87.68 & 82.12 & 50.52 & 95.07 & 49.21 \\
\hline & & & & & \\
\hline
\end{tabular}

If we do not reduce the outputs indicators, we obtain the results illustrated in Table 4. In this table we identified five CCR models of DEA. We have pointed out that the quality indicators are measured by ratios and, according to Hollingsworth and Smith [48], 
the specification of the $\mathrm{BBC}$ form of DEA model is the best option since the ratio entails assuming constant returns to scale. But these authors (page 734) also affirm that "the ratio approach will not lead to major difficulties in practice" and when the ratios are "based on different denominators, they have the virtue of being independent of the size of the unit and therefore facilitate comparison between units." Moreover, the denominator of our ratios is not related to population or any other size measures, so we decided to adopt the CCR model which does not cause any problems and to make it easier to compare the results of the different models.

In the first, we considered the three supply-side indicators (hours, vehicles-km, and seats); in the second, the demand-side measure (passengers); in the third, the three quality outputs (frequency, comfort, and accessibility); finally, permitting a global analysis of bus operators, in the fourth, the eight outputs; in the fifth, the three factors obtained by principal components analysis.

The average of technical efficiencies were situated at $87.68 \%, 82.12 \%, 50.52 \%, 95.07 \%$ and $49.21 \%$. The results show that the efficiency indeces are determined by the outputs employed. The DEA supply and DEA demands report a similar efficiency index but it may not be at all related to quality or to overall analysis. The relation of supply and demand indicators and the nonrelation with quality variables is manifested in the composition of the three factors obtained in the principal components analysis.

Analysis of the units shows that in the DEA supply there are 15 efficient municipalities, and among these 15 efficient supply units, 7 are demand efficient units and 6 are quality efficient units. Moreover, one municipality, Castellón, is quality efficient but not supply and demand efficient.

If we consider all outputs, 17 units are overall efficient; in other words, they are all units that have been efficient in one of the supply, demand, or quality models, plus another municipality that is inefficient in all other models.

In the DEA-3 factors, only 6 DMUs are overall efficient and correspond to those municipalities that exhibit scores equal to one within all the DEA models. This result leads us to conclude that principal component analysis is a robustness procedure to reduce the number of outputs variables and allows us to perform an overall analysis with fewer outputs, which increases the degrees of freedom but with all the information considered when using all the proposed variables.

\subsection{Statistical Selection of Social Indicators}

We chose a 3-stage process to detect the repercussion of certain external circumstances on the levels of efficiency. This process comprises the following stages.

(i) The first stage is to obtain the BCC efficiency index, taking into consideration the outputs defined by the three factors obtained in the previous stage. In addition, we ran the DEA model under CRS and compared these efficiency scores with those obtained in VRS estimation. The majority of the units emerged with different scores under the two assumptions. We then assumed VRS in order to isolate the impact of operation size, or in other words, to eliminate the differences caused between units by scale economies. Moreover, since the outputs are whole numbers, it is not compulsory to use a CCR model. We also selected an input-oriented BCC-DEA model because it was necessary to transform negative outputs factors into positive ones. 
Table 5: Regression of the BCC efficiency index on the external circumstances.

\begin{tabular}{lcc}
\hline Variable & Coefficient & $P$-value \\
\hline Constant & 270.3482 & .010 \\
Population density & -0.0113088 & .030 \\
Rent per capita & -1.74293 & .616 \\
Private vehicles in circulation & 0.0000792 & .115 \\
Average commercial speed & -2.444109 & .414 \\
Coeff. of intensity in rush hours & -128.2061 & .033 \\
km per routes served & -0.0000417 & .463 \\
Dummy existence alternative & -21.95711 & .410 \\
\hline & Log likelihood $=-91.816105$ & \\
\end{tabular}

Table 6: Comparison of DEA-BCC input-oriented models: effect of social indicators.

\begin{tabular}{|c|c|c|c|}
\hline Efficiency indices & Mean & Standard deviation & Efficient units \\
\hline DEA & 94.00 & 5.07538 & 6 \\
\hline DEA with uncontrollable inputs & 94.91 & 4.98110 & 9 \\
\hline \multicolumn{4}{|c|}{ Effect of social indicators } \\
\hline Variation & $0.91(0.97 \%)$ & $-0.09428(1.86 \%)$ & $3(50.00 \%)$ \\
\hline \multicolumn{4}{|c|}{$n=28$, Indices expressed in multiples of 100} \\
\hline
\end{tabular}

(ii) In the second stage, a Tobit model or censored regression was estimated, with the purpose of detecting if the efficiency measures are related more to exogenous factors or social indicators, which are expected to be related to the inefficiency levels obtained with DEA.

(iii) Once the impact of the external circumstances on the inefficiency of the towns has been demonstrated, they will be introduced as non controllable inputs in the final model.

As can be seen in the results given in Table 5, a partial influence of the surroundings on the level of efficiency was obtained, although the explanatory power of the model is too low, at $8 \%$. Specifically, the variables population density and coefficient of intensity in rush hours prove to be statistically significant at the 5\% level with a negative effect on the BCC index. Nolan [49] observed a negative relation between technical efficiency and the last temporal service characteristics. The other variables were revealed as no significant.

An estimation of the effect of social indicators on the efficiency index was carried out. Table 6 shows the results of comparing the BCC input-oriented models with and without uncontrolled inputs.

A comparison of these results shows that the effect of population density and intensity in rush hours on municipal performance means an increase of 1 point in the efficiency indices, a decrease of 0.095 points in the variability existing between municipal indices, and an increase of $50 \%$ with respect to the units classified as efficient in the model without uncontrollable inputs.

With the partial proof of a relation between the exogenous variables and efficiency, we went on to perform the analysis considering the two variables as noncontrollable inputs. 
Table 7: CCR- and BCC-efficiency index for Spanish public bus transport.

\begin{tabular}{|c|c|c|c|}
\hline Municipalities & Technical efficiency (CRS scores) & $\begin{array}{c}\text { Pure technical efficiency (VRS } \\
\text { scores-input oriented) }\end{array}$ & Scale efficiency \\
\hline Alcalá & $42.44 \%$ & $89.68 \%$ & $47.32 \%$ \\
\hline Burgos & $10.96 \%$ & $89.51 \%$ & $12.24 \%$ \\
\hline Castellón & $63.99 \%$ & $97.52 \%$ & $65.62 \%$ \\
\hline Ciudad Real & $100.00 \%$ & $100.00 \%$ & $100.00 \%$ \\
\hline Gijón & $5.25 \%$ & $88.39 \%$ & $5.94 \%$ \\
\hline Girona & $47.98 \%$ & $97.17 \%$ & $49.38 \%$ \\
\hline Lugo & $100.00 \%$ & $100.00 \%$ & $100.00 \%$ \\
\hline Lleida & $30.39 \%$ & $90.05 \%$ & $33.75 \%$ \\
\hline Madrid & $100.00 \%$ & $100.00 \%$ & $100.00 \%$ \\
\hline Mieres & $70.08 \%$ & $97.77 \%$ & $71.68 \%$ \\
\hline Oviedo & $100.00 \%$ & $100.00 \%$ & $100.00 \%$ \\
\hline Palma Mallor. & $12.65 \%$ & $88.65 \%$ & $14.27 \%$ \\
\hline Ponferrada & $100.00 \%$ & $100.00 \%$ & $100.00 \%$ \\
\hline Sabadell & $11.62 \%$ & $92.49 \%$ & $12.56 \%$ \\
\hline Salamanca & $11.70 \%$ & $89.65 \%$ & $13.05 \%$ \\
\hline San Cugat & $100.00 \%$ & $100.00 \%$ & $100.00 \%$ \\
\hline San Sebastián & $55.98 \%$ & $100.00 \%$ & $55.98 \%$ \\
\hline Santander & $6.42 \%$ & $93.33 \%$ & $6.88 \%$ \\
\hline Santiago Com. & $27.87 \%$ & $91.82 \%$ & $30.35 \%$ \\
\hline Sevilla & $1.44 \%$ & $84.60 \%$ & $1.70 \%$ \\
\hline Toledo & $100.00 \%$ & $100.00 \%$ & $100.00 \%$ \\
\hline Torrelavega & $100.00 \%$ & $100.00 \%$ & $100.00 \%$ \\
\hline Valladolid & $22.16 \%$ & $93.30 \%$ & $23.75 \%$ \\
\hline Zaragoza & $3.79 \%$ & $93.86 \%$ & $4.04 \%$ \\
\hline Average efficiency & $51.03 \%$ & $94.91 \%$ & $52.02 \%$ \\
\hline Efficiency units & 8 & 9 & 8 \\
\hline Inefficiency units & 16 & 15 & 16 \\
\hline
\end{tabular}

\section{Analysis and Results}

\subsection{Efficiency Index}

Table 7 reports the findings from CRS and VRS analysis of the bus operator data. Technical efficiency can be examined by decomposing it into pure technical efficiency and scale efficiency. The average index of technical efficiency was situated at $51.03 \%$, of pure technical efficiency at $94.91 \%$, and of scale efficiency at $52.02 \%$. Decomposition indicates that 15 municipalities $(62.5 \%)$ were technical inefficient. However, the means show that most of the technical inefficiency is in form of scale inefficiency. 
Table 8: Potential average savings and increases (BCC input-oriented model).

\begin{tabular}{lc}
\hline & Percentage variation \\
\hline Input1 & $-5.41 \%$ \\
Input2 & $-7.00 \%$ \\
Input3 & $-4.80 \%$ \\
\hline Average inputs' slacks & $5.74 \%$ \\
\hline Factor1 & $2.77 \%$ \\
Factor2 & $14.93 \%$ \\
Factor3 & $45.66 \%$ \\
\hline Average outputs' slacks & $21.12 \%$ \\
\hline
\end{tabular}

Among the efficient bus operators, we can indicate that

(i) eight units (33.33\%) are technical efficient (pure technical and scale). These municipalities are Ciudad Real, Lugo, Madrid, Oviedo, Ponferrada, San Cugat, Toledo, and Torrelavega;

(ii) one unit (4.17\%), San Sebastián, is only pure technical efficient.

The purpose of Table 8 is to summarize the main sources of inefficiencies, as observed amongst inputs and outputs, for all municipalities. The possible mean reductions of inputs are around $5.74 \%$. For instance, municipalities could have reduced their staff by $5.41 \%$, their buses by $4.80 \%$, and the fuel by $7 \%$.

With respect to the outputs, it is also detected that the service is performed almost optimally as regards frequency, real supply- and demand-side (FACTOR1), because the slack that it presents is on average $2.77 \%$. On the other hand, the quality of the service needs to increase, and without requiring any additional inputs, in the aspects of comfort and safetyan increase of $14.93 \%$ of FACTOR2 — and especially, in accessibility—an increase of $45.66 \%$ of FACTOR3.

\subsection{Private versus Public Ownership}

These results lead to an interest in examining whether the type of ownership, public versus. private, has a significant impact on the level of efficiency shown by the different towns in the BCC input-oriented model. To do so, we adopted the procedure of Brocket and Golany [50] consisting of

(i) estimation of the production frontier for towns with private ownership separately from the ones with public ownership;

(ii) application of the Mann Whitney test, with the following null hypothesis:

Ho: The two types of ownership, public and private, present the same level of efficiency.

According to the results yielded by the statistics of the test estimated (Table 9), we cannot reject the null hypothesis that the levels of efficiency for private firms are identical to those of public agencie; so the different types of ownership of the service do not lead to more optimal behavior. These results have been supported by Fazioli et al. [51] in Italy and Zullo [52] in US but provide a controversial issue with other studies, for example, Tone and Sawada [16], Cowie and Asenova [15], or Roy and Yvrande-Billon [53]. 
Table 9: Statistics of contrast.

\begin{tabular}{lcc}
\hline & Statician & $P$-value \\
\hline \multirow{2}{*}{ Mann-Whitney } & $U=51$ & .131 \\
& $W=129$ &. \\
\hline
\end{tabular}

\section{Conclusions}

The growing interest in the evaluation of the technical efficiency of public services is especially important in the municipal area, because of its influence on the quality of life of citizens. Public bus transport, one of the municipal competences, is a service for which there is a particular interest in introducing improvements in its management owing to the characteristics surrounding its performance.

De Borger et al. [12] provided a comprehensive survey of literature on production frontiers for transit operators and found that many important issues remain unresolved, like the specification of outputs or the characteristics outside the control of the operators, and so forth.

In this paper, we established a procedure of analysis that allows us to analyze the bus services accounting for, first, supply, demand, and quality output measures that permit us to capture all the economic motives for providing the services, and second, characteristics of the heterogeneity of the transport output, as an integral part of the technology description.

To reduce the number of outputs we used a principal component factor analysis that allowed us to make an overall analysis which increases the degrees of freedom but with all the information considered when using all the proposed variables.

To identify the elements of environmental heterogeneity, we applied a Tobit regression and found that there was a negative effect of population density and peak-to-base ratio on technical efficiency. These two variables, population density and peak-to-base ratio, were considered as noncontrollable inputs in the analysis.

As regards the results, analysis using the DEA technique reveals that

(i) the average index of technical efficiency was situated at $51.03 \%$, of pure technical efficiency at $94.91 \%$, and of scale efficiency at $52.02 \%$;

(ii) fifteen municipalities $(62.5 \%)$ were technical inefficient. However, the means show that most of the technical inefficiency is in the form of scale inefficiency;

(iii) among the efficient bus operators, eight units (33.33\%) are technical efficient (pure technical and scale), and one unit (4.17\%), San Sebastián, is only pure technical efficient;

(iv) the analysis of slacks reveals surplus resources of around $6 \%$ as well as an important increase in the quality of the service in terms of comfort, safety, and especially accessibility;

(v) the ownership (public versus private) does not in itself entail a higher attainment of levels of efficiency.

\section{References}

[1] D. Prior, "Management control in public transport," Spanish Review of Accounting and Finance, vol. 59, pp. 429-455, 1989 (Spanish).

[2] J. Berechman, Public Transit Economics and Deregulation Policy, North-Holland, Amsterdam, The Netherlands, 1993. 
[3] J. Preston, "Regulation policy in land passenger transportation in Europe," in Proceedings of the 7th International Conference on Competition and Ownership of Land Transport, Molde, Norway, June 2001.

[4] D. M. van de Velde, "Organisational forms and entrepreneurship in public transport: classifying organisational forms," Transport Policy, vol. 6, no. 3, pp. 147-157, 1999.

[5] D. M. Dalen and A. Gómez-Lobo, "Yardsticks on the road: regulatory contracts and cost efficiency in the Norwegian bus industry," Transportation, vol. 30, no. 4, pp. 371-386, 2003.

[6] M. Piacenza, "Regulatory contracts and cost efficiency: stochastic frontier evidence from the Italian local public transport," Journal of Productivity Analysis, vol. 25, no. 3, pp. 257-277, 2006.

[7] C. Cambini and D. Vannoni, "Restructuring public transit systems: evidence on cost properties from medium and large-sized companies," Review of Industrial Organization, vol. 31, no. 3, pp. 183-203, 2007.

[8] J. Pucher, "A decade of change for mass transit," Transportation Research Record, no. 858, pp. 48-57, 1982.

[9] M. G. Karlaftis, J. S. Wasson, and E. S. Steadham, "Impacts of privatization on the performance of urban transit systems," Transportation Quarterly, vol. 51, no. 3, pp. 67-79, 1997.

[10] H. L. Boschken, "Behavior of urban public authorities operating in competitive markets," Administration and Society, vol. 31, no. 6, pp. 726-758, 2000.

[11] K. Obeng and G. A. Azam, "Allocative distortions from transit subsidies," International Journal of Transport Economics, vol. 22, no. 1, pp. 15-34, 1995.

[12] B. De Borger, K. Kerstens, and 1. Costa, "Public transit performance: what does one learn from frontier studies?" Transport Reviews, vol. 22, no. 1, pp. 1-38, 2002.

[13] R. Levaggi, "Parametric and non-parametric approach to efficiency: the case of urban transport in Italy," Studi Economici, vol. 49, no. 53, pp. 67-88, 1994.

[14] K. Obeng and G. A. Azam, "Type of management and subsidy-induced allocative distortions in urban transit firms: a time series approach," Journal of Transport Economics and Policy, vol. 31, no. 2, pp. 193 209, 1997.

[15] J. Cowie and D. Asenova, "Organisation form, scale effects and efficiency in the British bus industry," Transportation, vol. 26, no. 3, pp. 231-248, 1999.

[16] K. Tone and T. Sawada, "An efficiency analysis of public versus private bus transportation enterprises," in Proceedings of the 12th IFORS International Conferences on Operational Research, pp. 357365, Athens, Greece, June 1990.

[17] K. Obeng, G. A. Azam, and R. Sakano, Modeling Economic Inefficiency Caused by Public Transit Subsidies, Praeger, Westport, Conn, USA, 1997.

[18] V. Pina and L. Torres, "Analysis of the efficiency of local government services delivery. An application to urban public transport," Transportation Research Part A, vol. 35, no. 10, pp. 929-944, 2001.

[19] B. Dervaux, K. Kerstens, and P. V. Eeckaut, "Radial and nonradial static efficiency decompositions: a focus on congestion measurement," Transportation Research Part B, vol. 32, no. 5, pp. 299-312, 1998.

[20] B. Thiry and H. Tulkens, "Allowing for inefficiency in parametric estimation of production functions for urban transit firms," Journal of Productivity Analysis, vol. 3, no. 1-2, pp. 45-65, 1992.

[21] K. Kerstens, "Decomposing technical efficiency and effectiveness of French urban transport," Annales d'Economie et de Statisque, no. 54, pp. 129-155, 1999.

[22] J. Odeck and A. Alkadi, "Evaluating efficiency in the Norwegian bus industry using data envelopment analysis," Transportation, vol. 28, no. 3, pp. 211-232, 2001.

[23] K.-P. Chang and P.-H. Kao, "The relative efficiency of public versus private municipal bus firms: an application of data envelopment analysis," Journal of Productivity Analysis, vol. 3, no. 1-2, pp. 67-84, 1992.

[24] X. Chu, G. J. Fielding, and B. W. Lamar, "Measuring transit performance using data envelopment analysis," Transportation Research Part A, vol. 26, no. 3, pp. 223-230, 1992.

[25] J. F. Nolan, P. C. Ritchie, and J. E. Rowcroft, "Identifying and measuring public policy goals: ISTEA and the US bus transit industry," Journal of Economic Behavior E Organization, vol. 48, no. 2, pp. 291304, 2002.

[26] M. G. Karlaftis, "A DEA approach for evaluating the efficiency and effectiveness of urban transit systems," European Journal of Operational Research, vol. 152, no. 2, pp. 354-364, 2004.

[27] P. A. Viton, "Changes in multi-mode bus transit efficiency, 1988-1992," Transportation, vol. 25, no. 1, pp. 1-21, 1998.

[28] M. P. Boilé, "Estimating technical and scale inefficiencies of public transit systems," Journal of Transportation Engineering, vol. 127, no. 3, pp. 187-194, 2001. 
[29] Y. J. Nakanishi and J. R. Norsworthy, "Assessing efficiency of transit service," in Proceedings of the IEEE Engineering Management Society (EMS '00), pp. 133-140, Albuquerque, Minn, USA, August 2000.

[30] A. Afonso and C. Scaglioni, "Public services efficiency provision in Italian regions: a non-parametric analysis," SSRN working paper, Technical University of Lisbon, Lisbon, Portugal, 2005.

[31] B. B. Margari, F. Erbetta, C. Petraglia, and M. Piacenza, "Regulatory and environmental effects on public transit efficiency: a mixed DEA-SFA approach," Journal of Regulatory Economics, vol. 32, no. 2, pp. 131-151, 2007.

[32] M.-M. Yu, "Measuring the efficiency and return to scale status of multi-mode bus transit-evidence from Taiwan's bus system," Applied Economics Letters, vol. 15, no. 8, pp. 647-653, 2008.

[33] A. K. Boame, "The technical efficiency of Canadian urban transit systems," Transportation Research Part E, vol. 40, no. 5, pp. 401-416, 2004.

[34] T. Holvad, J. L. Hougaard, D. Kronborg, and H. K. Kvist, "Measuring inefficiency in the Norwegian bus industry using multi-directional efficiency analysis," Transportation, vol. 31, no. 3, pp. 349-369, 2004.

[35] R. Färe and C. A. K. Lovell, "Measuring the technical efficiency of production," Journal of Economic Theory, vol. 19, no. 1, pp. 150-162, 1978.

[36] M. J. Farrell, "The measurement of productive efficiency," Journal of the Royal Statistics Society Series A, vol. 120, no. 3, pp. 253-281, 1957.

[37] A. Charnes, W. W. Cooper, and E. Rhodes, "Measuring the efficiency of decision making units," European Journal of Operational Research, vol. 2, no. 6, pp. 429-444, 1978.

[38] R. D. Banker, A. Charnes, and W. W. Cooper, "Some models for estimating technical and scale inefficiencies in data envelopment analysis," Management Science, vol. 30, no. 9, pp. 1078-1092, 1984.

[39] R. D. Banker and R. C. Morey, "Efficiency analysis for exogenously fixed inputs and outputs," Operations Research, vol. 34, no. 4, pp. 513-521, 1986.

[40] R. D. Banker and R. C. Morey, "The use of categorical variables in data envelopment analysis," Management Science, vol. 32, no. 12, pp. 1613-1627, 1986.

[41] R. Carrington, N. Puthucheary, D. Rose, and S. Yaisawarng, "Performance measurement in government service provision: the case of police services in New South Wales," Journal of Productivity Analysis, vol. 8, no. 4, pp. 415-430, 1997.

[42] B. Golany and Y. Roll, "An application procedure for DEA," Omega, vol. 17, no. 3, pp. 237-250, 1989.

[43] R. Sakano, K. Obeng, and G. A. Azam, "Subsides and inefficiency: stochastic frontier approach," Contemporary Economic Policy, vol. 15, no. 3, pp. 113-127, 1997.

[44] J. H. Miller, "The use of performance-base methodologies for the allocations of transit operating funds," Traffic Quarterly, vol. 34, no. 4, pp. 555-585, 1980.

[45] R. D. Banker, H. Chang, and W. W. Cooper, "Simulation studies of efficiency, returns to scale and misspecification with nonlinear functions in DEA," Annals of Operations Research, vol. 66, pp. 233-253, 1996.

[46] A. Iqbal Ali and L. M. Seiford, "Translation invariance in data envelopment analysis," Operations Research Letters, vol. 9, no. 6, pp. 403-405, 1990.

[47] J. T. Pastor, "Translation invariance in data envelopment analysis: a generalization," Annals of Operations Research, vol. 66, no. 2, pp. 91-102, 1996.

[48] B. Hollingsworth and P. Smith, "Use of ratios in data envelopment analysis," Applied Economics Letters, vol. 10, no. 11, pp. 733-735, 2003.

[49] J. F. Nolan, "Determinants of productive efficiency in urban transit," Logistics and Transportation Review, vol. 32, no. 3, pp. 319-342, 1996.

[50] P. L. Brocket and B. Golany, "Using rank statistics for determining programmatic efficiency differences in data envelopment analysis," Management Science, vol. 42, no. 3, pp. 466-472, 1996.

[51] R. Fazioli, M. Filippini, and P. Prioni, "Cost-structure and efficiency of local public transport: the case of Emilia Romagna bus companies," International Journal of Transport Economics, vol. 20, no. 3, pp. 305-324, 1993.

[52] R. Zullo, "Transit contracting reexamined: determinants of cost efficiency and resource allocation," Journal of Public Administration Research and Theory, vol. 18, no. 3, pp. 495-515, 2008.

[53] W. Roy and A. Yvrande-Billon, "Ownership, contractual practices and technical efficiency: the case of urban public transport in france," Journal of Transport Economics and Policy, vol. 41, no. 2, pp. 257-282, 2007. 


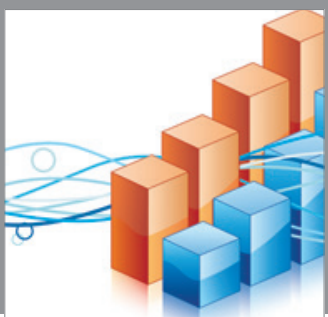

Advances in

Operations Research

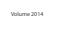

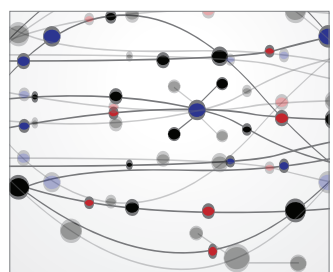

\section{The Scientific} World Journal
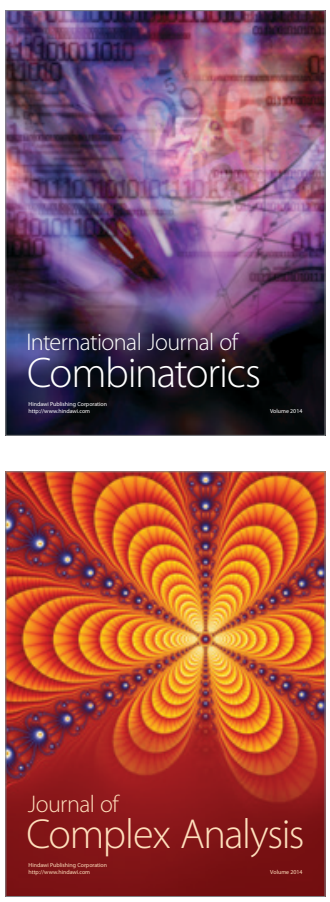

International Journal of

Mathematics and

Mathematical

Sciences
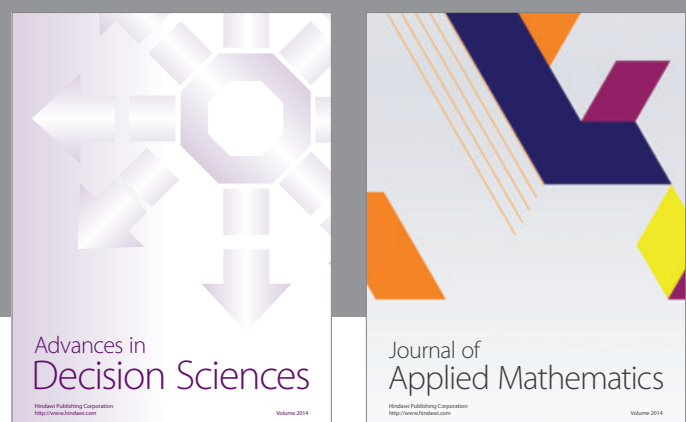

Journal of

Applied Mathematics
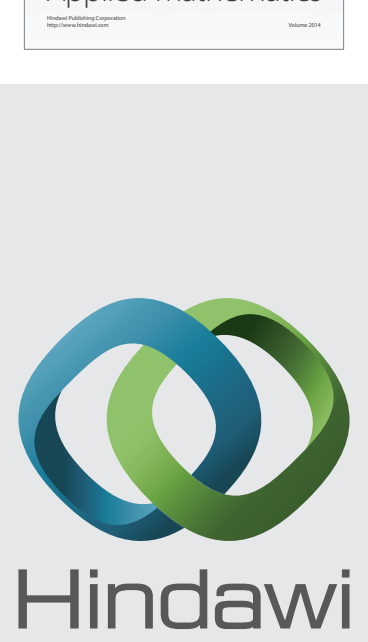

Submit your manuscripts at http://www.hindawi.com
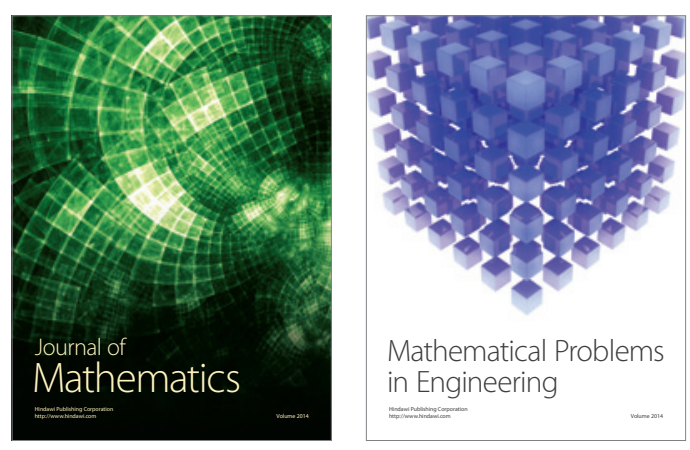

Mathematical Problems in Engineering
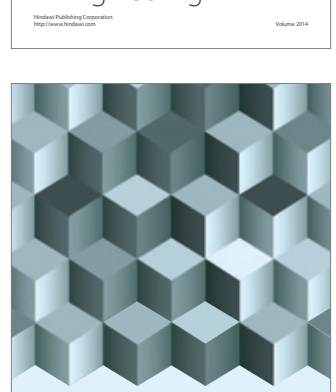

Journal of

Function Spaces
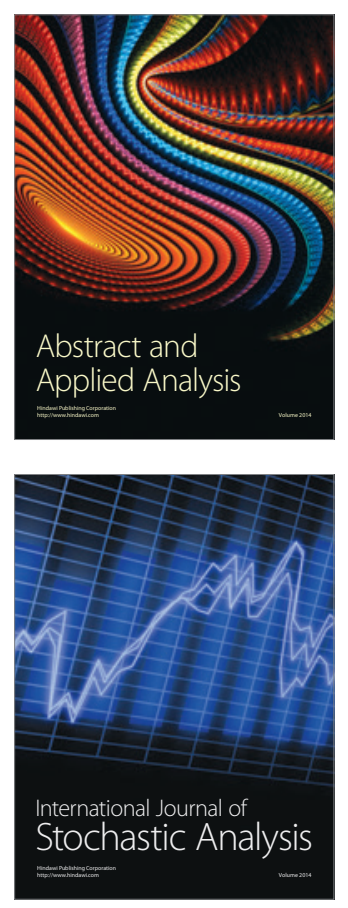

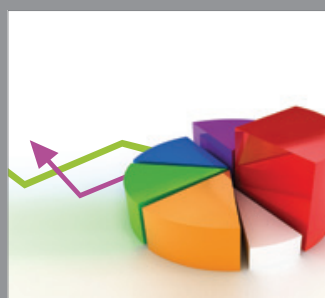

ournal of

Probability and Statistics

Promensencen
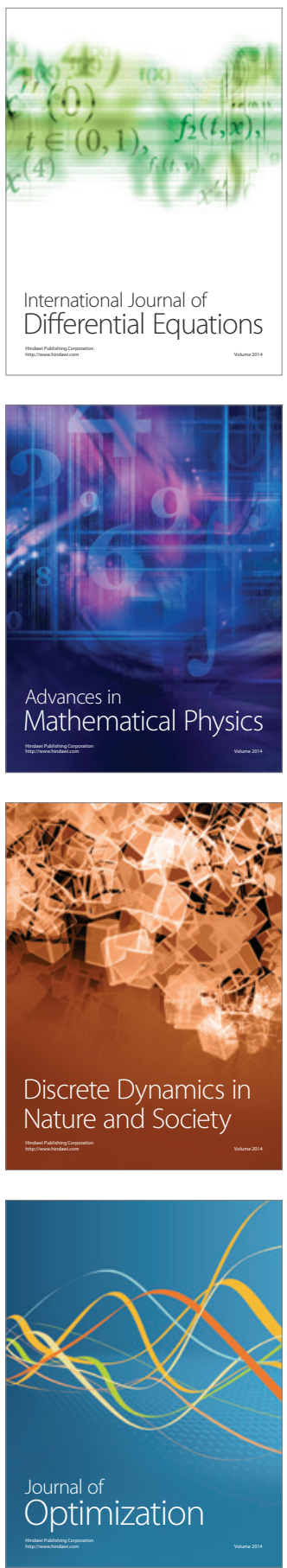